\title{
Antropologia e Saúde: entre o político e a produção do conhecimento
}

\author{
Anthropology and Health: between politics and the production \\ of knowledge
}

\author{
Antropología y Salud: entre el político y la producción \\ del conocimiento
}

\begin{abstract}
ANTROPOLOGIAS, SAÚDE E CONTEXTOS DE CRISE. Castro R, Engel C, Martins R, organizadoras. Brasília: Sobrescrita; 2018. 198 p. ISBN 978-85-93989-05-6.
\end{abstract}

doi: $10.1590 / 0102-311 \times 00201118$

Antropologias, Saúde e Contextos de Crise 1 é uma coletânea de textos organizada por Rosana Castro, Cíntia Engel \& Raysa Martins. Esta obra deriva-se de uma série de problematizações ao longo de diversos eventos científicos e grupos de pesquisa no que concernem aos diálogos entre antropologias, processo saúde-doença e sistemas terapêuticos, retratando mais precisamente o que foi discutido na II RAS (Reunião de Antropologia da Saúde) no ano de 2017, em Brasília.

A capa da obra indica o teor do conteúdo que será abordado nos capítulos. Foi ilustrada por uma pichação em uma parede com o seguinte dizer: "Vandalismo é a fila do SUS! Não confunda a reação do oprimido com a violência do opressor!". Em outras palavras, aponta os (des)serviços no campo da Saúde e suas relações com o (des)governo dos últimos anos, aspecto este tão importante na agenda de investigação das Ciências Sociais com o atual universo político e social do Estado brasileiro 2 .

Antropologias, Saúde e Contextos de Crise é um livro atual que consegue não somente acrescentar à produção do conhecimento no campo das
Ciências Sociais em Saúde, como também denunciar de modo crítico-reflexivo sobre os aspectos macro e microestruturais que engendram o processo saúde-doença no país. Ademais, o livro é emblemático ao ser publicado em ano eleitoral e, exatamente, na terceira década em que o Sistema Único de Saúde (SUS) legitima-se com a Constituição Federal de 1988 pela ideia central de que as pessoas possuem o direito à saúde. Isto é: "Este direito está ligado à condição de cidadania. (...) o SUS supõe uma sociedade solidária e democrática, movida por valores de igualdade e de equidade, sem discriminações ou privilégios" 3 (p. 43).

O início da obra possui três textos que contextualizam a dimensão da crise em saúde no Brasil. Após a apresentação do livro elaborada por Soraya Fleischer, as organizadoras e Sônia W. Maluf delatam inúmeros elementos de ordem política e econômica que historicamente afetaram/afetam a saúde pública brasileira, situando o campo antropológico diante dessa realidade.

Na sequência desses textos introdutórios, o livro foi dividido em três partes: I - Etnografias em Contextos de Crise; II - Antropologias da e na Saúde: Debates, Propostas e Impasses; III - Tecnologias de Engajamento: Conhecer, Fazer, Resistir; cada uma composta por quatro capítulos.

$\mathrm{Na}$ Parte I, as organizadoras reuniram textos que apontam de que formas os empreendimentos etnográficos conseguem iluminar situações do cotidiano no que diz respeito ao processo saúde-doença em dadas microrrealidades sociais. As organizadoras trazem capítulos sobre 
o "vivido" e o "experienciado" no contexto dos cuidados básicos (e precários) de saúde em comunidade, em relação aos impactos da Reforma Previdenciária, nas dificuldades de reconhecimento de direitos à saúde na condição de brasileiros no exterior, bem como nas limitações da Reforma Psiquiátrica.

Na Parte II, há discussões sobre a legitimação e o ofício do campo antropológico na Saúde. Nesta seção, abordam-se experiências, limites e potencialidades de diálogos ou estranhamentos sobre o processo de ensino-aprendizagem da/na Antropologia e suas relações com a área e as políticas em Saúde.

Na Parte III, a obra abrange uma série de questões relacionadas ao valor do campo antropológico no sentido de compreender as lógicas e as visões de mundo de determinados grupos e contextos sociais. Comunidades quilombolas, homens e suas práticas sexuais em face do HIV/ aids, assim como "pessoas com deficiência", fazem parte dos principais eixos de análise nessa seção, que ajuda entender a necessidade de desnaturalizar e questionar os modos de lidar com o Outro, ou, ainda, fornece outras possibilidades de ser e agir no mundo.

Com base na produção acadêmica sobre as relações entre Antropologia e Saúde no país ao longo das últimas décadas 4,5,6,7, pode-se afirmar que Antropologias, Saúde e Contextos de Crise torna-se uma referência indispensável aos docentes, pesquisadores e formuladores de políticas no campo da Saúde Pública. Ainda que o livro reitere inúmeros debates já amplamente discutidos no campo das Ciências Sociais em Saúde, podese afirmar que a obra avança em defesa do SUS e da qualidade dos seus serviços. Isso se justifica na medida em que deixa explícita a necessidade de revelar ou fazer emergir como a redução dos recursos públicos associada aos "bastidores" privatistas e coorporativos impactam negativamente na saúde da população, sobretudo nos grupos sociais que historicamente mais carecem de cuidado. Desse modo, a obra estimula os leitores a pensarem e se mobilizarem em torno de que as atuais articulações político-econômicas para o setor Saúde (mas não somente...) possuem intenções de desmonte do SUS.

Indubitavelmente, o livro, portanto, configura-se pela perspectiva de Bourdieu ${ }^{8}$ em que o conhecimento dito "científico" nunca é politicamente isento. Em suma, ainda que a obra tenha sido compartimentada em seções específicas pela particularidade das discussões, a sua composição entre os capítulos consegue abranger uma série de aspectos que (des)mobilizam o cenário atual em Saúde e os lugares das antropologias nesse contexto. Assim, o livro caracteriza-se por um ato político e de resistência em todos os sentidos, uma vez que consegue oferecer ao leitor um equilíbrio entre a intervenção/atuação do campo antropológico e as realidades de vulnerabilidade e violências que marcam e afetam a população brasileira.

\section{Alan Camargo Silva 1}

1 Escola de Educação Física e Desportos, Universidade Federal do Rio de Janeiro, Rio de Janeiro, Brasil.

alan10@zipmail.com.br

\section{Informação adicional}

ORCID: Alan Camargo Silva (0000-0003-17295151).

1. Castro R, Engel C, Martins R, organizadores. Antropologias, saúde e contextos de crise. Brasília: Sobrescrita; 2018.

2. Lima M. A produção de conhecimento em tempos de conflito: o lugar das Ciências Sociais Rev Antropol (São Paulo) 2018; 61:95-102.

3. Paim JS. O que é o SUS. Rio de Janeiro: Editora Fiocruz; 2009.

4. Canesqui AM. Notas sobre a produção acadêmica de antropologia e saúde na década de 80 . In: Alves PC, Minayo MCS, organizadores. Saúde e doença: uma olhar antropológico. Rio de Janeiro: Editora Fiocruz; 1994. p. 13-32.

5. Canesqui AM. Os estudos de antropologia da saúde/doença no Brasil na década de 1990. Ciênc Saúde Coletiva 2003; 8:109-124.

6. Canesqui AM. Temas e abordagens das ciências sociais e humanas em saúde na produção acadêmica de 1997 a 2007. Ciênc Saúde Coletiva 2010; 15:1955-66.

7. Canesqui AM. Ciências sociais e saúde no Brasil. 2a Ed. São Paulo: Editora Hucitec; 2011.

8. Bourdieu P. Lições da aula. São Paulo: Editora Ática; 1994.

Recebido em 20/Out/2018

Versão final reapresentada em 14/Dez/2018 Aprovado em 27/Dez/2018 